Check for updates

Cite this: RSC Adv., 2018, 8, 5106

Received 6th December 2017

Accepted 22nd January 2018

DOI: $10.1039 / c 7 r a 13074 k$

rsc.li/rsc-advances

\section{An efficient mercapto-functionalized organic- inorganic hybrid sorbent for selective separation and preconcentration of antimony(III) in water samples}

\begin{abstract}
Nan You, $\uparrow^{a}$ Tian-Hong Liu, $\dagger^{b}$ Hong-Tao Fan (D) *a and Hua Shen*b
This work reported on the application of mercapto-functionalized silica-supported organic-inorganic hybrid sorbent as a solid phase extraction (SPE) extractant for effective separation and preconcentration of $\mathrm{Sb}$ (III) species in real water samples. The influences of $\mathrm{pH}$, sorbent amounts, flow rates and the concentration of eluent on the adsorption and desorption of $\mathrm{Sb}\left({ }_{111}\right)$ species had been evaluated. The recovery of $\mathrm{Sb}($ III) species at $\mathrm{pH} 5$ with $100 \mathrm{mg}$ mercapto-functionalized hybrid sorbent at the flow rate of $5.0 \mathrm{~mL} \mathrm{~min} \mathrm{~m}^{-1}$ was greater than $95 \%$ without interference from all of metal ions tested. The trapped $\mathrm{Sb}$ (III) species by extractant was then eluted with $5 \% \mathrm{HCl}$ solution at the flow rate of $5.0 \mathrm{~mL} \mathrm{~min}^{-1}$. The proposed procedure permitted large enrichment factors of about 200 and higher for $10 \mu \mathrm{g} \mathrm{L}^{-1}$ of $\mathrm{Sb}$ (III) species. The merits of analytical figures for the determination of $\mathrm{Sb}($ III) species were as follows: detection limit $(3 \sigma, n=11), 2 \mathrm{ng} \mathrm{L}{ }^{-1}$; precision, $1.6 \%(n=11)$ for $10 \mu \mathrm{g} \mathrm{L}^{-1}$ of Sb(III) species; the linear calibration curve presented in the concentration range of $1.0-200.0 \mu \mathrm{g} \mathrm{L}^{-1}$. The validity of the proposed procedure was checked by the analysis of standard reference materials. Excellent agreement between the analytical results and the certified values ( $t$-test at $95 \%$ confidence level) was found. The mercapto-functionalized hybrid sorbent as a SPE extractant was applied to the determination of Sb(II) species in various water samples with satisfactory results.
\end{abstract}

\section{Introduction}

Antimony ( $\mathrm{Sb}$ ) is increasingly considered to be a toxic heavy metal with possible carcinogenic effects on human health. ${ }^{1}$ Antimony contamination is receiving concerns with increasing knowledge on its environmental fates and toxicological characteristics. ${ }^{2}$ Antimony exists primarily as $\mathrm{Sb}(\mathrm{v})$ in oxic systems and $\mathrm{Sb}(\mathrm{III})$ in anoxic systems. ${ }^{3} \mathrm{Sb}(\mathrm{III})$ compounds have ten times higher acute toxicity than $\mathrm{Sb}(\mathrm{v})$ species. ${ }^{4}$ To understand the bioavailability and toxicity of $\mathrm{Sb}$, there is a need for reliable methods that enable the measurements of specific speciation of $\mathrm{Sb}$, especially for $\mathrm{Sb}$ (III) species.

Atomic fluorescence spectrometry is a simple and well available technique for the determination of $\mathrm{Sb}$ in real samples. ${ }^{5}$ However, its main problem is the low selectivity for the speciation of $\mathrm{Sb}$. Separation and preconcentration procedures can be applied to overcome this limitation. Solid-phase extraction (SPE) is one of widely used and fast emerging

${ }^{a}$ College of Chemistry, Chemical Engineering and Environmental Engineering, Liaoning University of Petroleum and Chemical Technology, Fushun, China. E-mail: httyf_77@163.com

${ }^{b}$ College of Applied Chemistry, Shenyang University of Chemical Technology, Shenyang, China. E-mail: yywwddsshh@sina.com

$\dagger$ The first two authors contributed equally to this paper. techniques for the separation and preconcentration of heavy metals due to its high enrichment factors, minimal costs, environmental friendliness, no need for emulsion, simplicity, flexibility, safety and ease of automation. ${ }^{6}$ Up to now, several kinds of SPE extractants, such as silica-based octyl sorbent, ${ }^{7}$ multi-walled carbon nanotubes, ${ }^{8}$ octyl-immobilized silicacoated magnetic nanoparticles, ${ }^{9}$ nano $\gamma$-alumina, ${ }^{10}$ singlewalled carbon ${ }^{11}$ and functionalized mesoporous silica, ${ }^{12}$ have been used to selectively retain the $\mathrm{Sb}$ (III) complex with ammonium pyrrolidine dithiocarbamate. Li et al. ${ }^{9}$ reported that $\mathrm{Sb}(\mathrm{III})$ forms a hydrophobic complex with ammonium pyrrolidine dithiocarbamate at $\mathrm{pH} 5.0$ and is retained on SPE extractant, whereas $\mathrm{Sb}(\mathrm{v})$ remain as the free species in aqueous solution. However, a few SPE extractants based on the direct retention of $\mathrm{Sb}$ (III) species have been developed. Zih-Perényi et al. ${ }^{13}$ used imino diacetic acid-ethyl cellulose for the selective separation and preconcentration of $\mathrm{Sb}$ (III). $\mathrm{SiO}_{2}$ nanoparticles functionalised with 1-(2-pyridylazo)-2-naphthol was used as SPE extractant for the preconcentration of trace amounts of $\mathrm{Sb}$ (III) in different water samples by Kaur and Gupta. ${ }^{14}$ Silica gel functionalized with 1,5-bis(di-2-pyridyl) methylene thiocarbonohydrazide was developed for the simultaneous separation, preconcentration and determination of antimony. ${ }^{15}$ Silica gel is used as a solid support for chelating groups because it is an inorganic material, 
stable under acidic conditions, nonswelling, high mass exchange characteristics and thermal resistance, ${ }^{\mathbf{1 6}}$ and relatively easy to be grafted with organosilanes containing functional groups by the co-condensation or self-condensation reactions. ${ }^{17}$ In our previous work, the immobilization of mercapto groups onto the surface of silica gel could be used for the selective removal of $\mathrm{Sb}$ (III) from aqueous solution due to the well-known phenomenon of hard-soft acid-bases theory. ${ }^{18}$ However, the simultaneous separation, preconcentration and determination of $\mathrm{Sb}$ (III) species in water samples using mercaptofunctionalized hybrid sorbents as the SPE extractant has not been reported.

The purpose of this work is to establish a new SPE method using mercapto-functionalized hybrid sorbents as the extractant for the separation, preconcentration and determination of $\mathrm{Sb}$ (III) in water samples prior to atomic fluorescence spectrometry measurement. The influences of experimental conditions (such as $\mathrm{pH}$, the flow rates of sample and eluent, and the concentration and volume of eluent solution) on the quantitative recoveries of $\mathrm{Sb}(\mathrm{III})$, have been investigated to establish an optimized SPE procedure. The validity of the proposed procedure has been evaluated by the analysis of certified reference materials. The separation, preconcentration and determination of $\mathrm{Sb}$ (III) species from real samples were also tested.

\section{Experimental}

\subsection{Chemicals}

The stock solutions of $\mathrm{Sb}(\mathrm{III})\left(1000 \mathrm{mg} \mathrm{\textrm {L } ^ { - 1 }}\right)$ and $\mathrm{Sb}(\mathrm{v})$ $\left(1000 \mathrm{mg} \mathrm{L}^{-1}\right)$ were prepared by potassium antimonyl tartrate and potassium hexahydroxyantimonate (Sigma-Aldrich), respectively. The working solutions were prepared by series dilution of the stock solutions immediately prior to their use. The other chemicals were obtained from Sinopharm Chemical Reagent Co., Ltd., Shanghai, China. All chemicals used in this work were of analytical grade and used without further purification. All the metal stock solutions $\left(1000 \mathrm{mg} \mathrm{L}^{-1}\right)$ were obtained from the National Research Center for Standard Materials (NRCSM, Beijing, China). The solution of sodium tetrahydroborate $0.7 \%$ was prepared by dissolving $7 \mathrm{~g}$ of $\mathrm{NaBH}_{4}$ powder and $4 \mathrm{~g}$ of $\mathrm{NaOH}$ in $1000 \mathrm{~mL}$ of water. A stock solution of potassium iodide $50 \%(\mathrm{w} / \mathrm{v})$ containing $\mathrm{L}$-ascorbic acid $10 \%(\mathrm{w} / \mathrm{v})$ was prepared by dissolving $25 \mathrm{~g}$ of $\mathrm{KI}$ and $5 \mathrm{~g}$ of L-ascorbic acid in a $50 \mathrm{~mL}$ of water. 8Hydroxyquinoline stock solution $1 \%(\mathrm{w} / \mathrm{v})$ was prepared by a dissolving $1 \mathrm{~g}$ of 8-hydroxyquinoline was in a $10 \mathrm{~mL}$ of methanol, and then diluted with water to make $100 \mathrm{~mL}$. All experimental and reagent solutions were prepared with deionized water. The solutions were prepared weekly and stored in a refrigerator. In order to prevent metal contamination, all the glassware was kept overnight in a $10 \%(\mathrm{v} / \mathrm{v}) \mathrm{HNO}_{3}$ solution with posterior cleaning with deionized water prior to use.

\subsection{Apparatus}

Fourier transmission infrared (FT-IR) spectra were recorded on a Spectrum One spectrometer (Perkin Elmer) with $\mathrm{KBr}$ pellets and a resolution of $1 \mathrm{~cm}^{-1}$. The samples were characterized by a scanning electron microscope (SEM) coupled to an energy dispersive spectrometer (EDS) with gold coating at the desired magnification (Shimadzu SSX-550). A commercial two channel hydride generation nondispersive atomic fluorescence spectrometer (HG-AFS, Model AFS-2202E, Beijing Haiguang Instrument Co., Beijing, China) equipped with a quartz argonhydrogen flame atomizer, a quartz gas-liquid separator, and coded high intensity hollow cathode lamps of $\mathrm{Sb}$ were used for the measurement of $\mathrm{Sb}$ (III) and total $\mathrm{Sb}$ concentrations in solution according to the steps described by Deng et al. ${ }^{19}$

\subsection{Synthesis of the sorbent}

Mercapto-functionalized hybrid sorbent was prepared by a twostep acid-base catalyzed sol-gel process as previously reported in the literature. ${ }^{20}$ Mercapto-functionalized hybrid sorbent was prepared by the following process: tetraethoxysilane (TEOS) was mixed with an acidic aqueous solution by using TEOS and water at the volume ratio of $2: 1$ at $\mathrm{pH} 2$ with the addition of $6 \mathrm{~mol} \mathrm{~L}^{-1}$ $\mathrm{HCl}$ solution. The mixture was stirred for $20 \mathrm{~min}$ at room temperature to initiate the hydrolysis reaction. Next, $30 \mathrm{wt} \%$ of ammonium hydroxide was poured into the mixture to induce the condensation reaction. The transparent solution became turbid, indicating that the colloidal particles were formed. The obtained sorbent was left for a night and rinsed with 60/40 (v/v) of ethanol/water for $12 \mathrm{~h}$. The precipitate was filtered through a membrane filter and washed with deionized water. Thus, formed mercapto-functionalized hybrid sorbent was obtained after drying under vacuum at $60{ }^{\circ} \mathrm{C}$ for $16 \mathrm{~h}$. The mercaptofunctionalized hybrid sorbent was sieved to obtain the particle size between 100 and 200 meshes. The textural properties of mercapto-functionalized hybrid sorbent were characterized by FT-IR spectra and SEM-EDS.

\subsection{Samples}

$100 \mathrm{mg}$ of stream sediment certified reference material (GBW07309) was accurately weighed into a beaker and a mixture of concentrated hydrochloric acid $(24 \mathrm{~mL})$ and nitric acid $(8.0 \mathrm{~mL})$ was added. The beaker covered with a watch glass was evaporated on a hot plate almost to dryness. Then, $8.0 \mathrm{~mL}$ of mixed acid solution was added to the residue. After cooling, the mixture was filtered through a glass filter. The sample and $5 \mathrm{~mL}$ of $10 \%$ vitamin $\mathrm{C}$ solution was mixed, and then the mixture solution was diluted to $25 \mathrm{~mL}$ with deionized water. The $\mathrm{pH}$ of the appropriate aliquots of the solution was adjusted to 5.0. The surface river water and lake water samples were collected from Hun River and Nan Lake, Shenyang, China in May 2016. Samples were filtrated immediately through nitrocellulose membrane (pore size: $0.45 \mu \mathrm{m}$, Sartorius, Germany) and were acidified with $\mathrm{HCl}$ to $\mathrm{pH} 2$ for conservation. All the samples were stored in polyethylene bottles, kept in the refrigerator at $4{ }^{\circ} \mathrm{C}$ before use and filtered prior to analytical procedure. Tap water samples were taken from our research laboratory without pretreatment. Before SPE procedure, the samples were adjusted to $\mathrm{pH} 5.0$ according to optimized experiment conditions. 


\subsection{Preconcentration procedures}

The separation and preconcentration studies were carried out in a packed-bed system. The stopcock of the glass column (100 $\mathrm{mm}$ in length and $10 \mathrm{~mm}$ in diameter) was covered with a fritted glass disc. A total of $100 \mathrm{mg}$ of extractant was slurred in water, and then poured into the column. A small amount of glass wool was placed on the disc to prevent loss of the sorbents during sample loading. The column height (adsorption bed) was about $15 \mathrm{~mm}$. It was treated successively with $2 \mathrm{~mol} \mathrm{~L}^{-1} \mathrm{HCl}$ and water. The column was preconditioned by passing a blank solution and then a solution containing $2.5 \mu \mathrm{g}$ of $\mathrm{Sb}$ (III) in a volume of $250 \mathrm{~mL}$ was passed through the column at a flow rate of $5.0 \mathrm{~mL} \mathrm{~min}^{-1}$ (controlled by a peristaltic pump) after adjusting $\mathrm{pH}$ 5.0. The column was washed with $5 \mathrm{~mL}$ water and then eluted with $5 \mathrm{~mL}$ of $5 \% \mathrm{HCl}$. The desorbed $\mathrm{Sb}(\mathrm{III})$ in eluent was measured by HG-AFS.

\section{Results and discussion}

\subsection{Sorbent characterization}

The mercapto-functionalized hybrid sorbent was characterized by FT-IR spectrum as shown in Fig. 1a. The FT-IR spectrum exhibits the stretching vibrational absorption bands for the corresponding organosilane functionalities such as $\mathrm{S}-\mathrm{H}$ stretching vibrations from thiol groups at $2561 \mathrm{~cm}^{-1}$ and $\mathrm{C}-\mathrm{H}$ symmetric stretching vibrations, asymmetric stretching vibrations and bending vibration from mercaptopropyl groups at 2933, 2866 and $1410 \mathrm{~cm}^{-1}$, which are the characteristic absorption peaks of mercaptopropyl groups. ${ }^{21}$ The peaks at 3448 and $1632 \mathrm{~cm}^{-1}$ reflect the stretching vibration and bending vibration of $\mathrm{O}-\mathrm{H}$ bond of hydroxy remaindered in sorbent. The peaks at 1086, 804 and $467 \mathrm{~cm}^{-1}$ come from the stretching vibrations of $\mathrm{Si}-\mathrm{O}-\mathrm{Si}, \mathrm{Si}-\mathrm{O}-\mathrm{Si}$ and $\mathrm{Si}-\mathrm{O}$ groups, respectively. ${ }^{22}$ It could be ascertained that the mercaptopropyl group was successfully grafted onto the surface of silica gel.

It can be seen in Fig. 1b that SEM micrographs for mercaptofunctionalized hybrid sorbent indicate loose aggregate morphology consisting of irregularly shaped particles with a broad size distribution varying from 100 to $1000 \mathrm{~nm}$, which tend to form larger accumulations. EDS was used in order to evaluate the elemental composition of the prepared mercaptofunctionalized hybrid sorbent. Fig. 1c indicates the presence of the S-peak, which is characteristic for the mercapto group $(-\mathrm{SH})$. Based on the EDS results, it could be concluded that the mercaptopropyl groups were successfully attached to the surfaces of the silica.

\subsection{Effect of $\mathbf{p H}$}

The $\mathrm{pH}$ of the aqueous solution plays an important role in the preconcentration of the analytes by SPE due to the enrichment of heavy metal ions based on chelation. The concentration of hydrogen ion significantly affects the formation of metal-ligand complex. The effects of $\mathrm{pH}$ on the preconcentration of $10 \mu \mathrm{g}$ each of $\mathrm{Sb}(\mathrm{III})$ and $\mathrm{Sb}(\mathrm{v})$ present in 1 litre of solution were investigated at the pH range 3-9, meanwhile keeping the other parameters constant. The deposition percentage of analytes depends on the
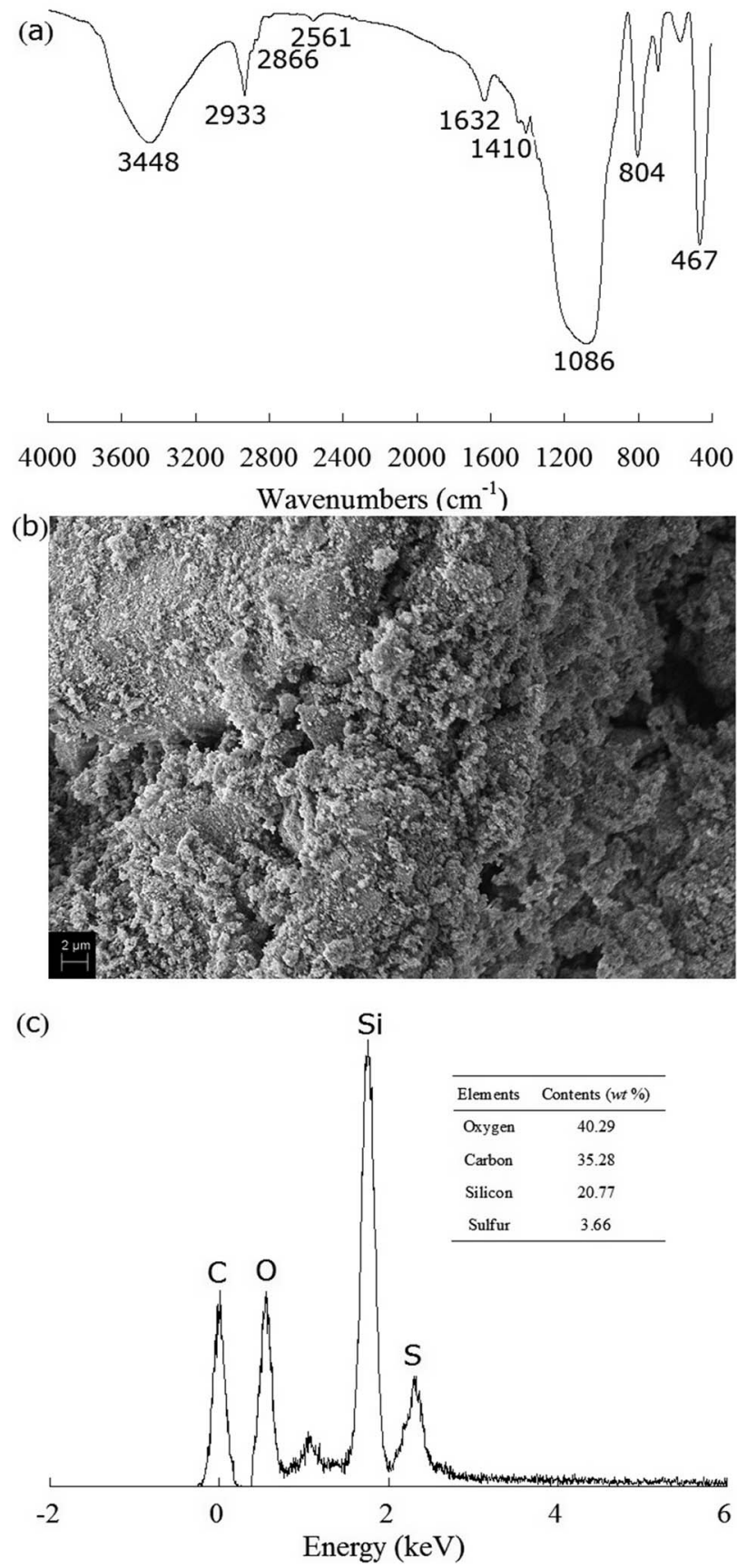

Fig. 1 (a) IR spectrum, (b) SEM image and (c) EDS spectra of mercaptofunctionalized hybrid sorbent.

sample pH as shown in Fig. 2. The high deposition percentage of $\mathrm{Sb}$ (III) was found to be constant in the $\mathrm{pH}$ range of 3-9. Low enrichment efficiency of $\mathrm{Sb}(\mathrm{v})$ was achieved at a whole $\mathrm{pH}$ range investigated. The high deposition percentage of $\mathrm{Sb}$ (III) (>99\%) and low enrichment efficiency of $\mathrm{Sb}(\mathrm{v})$ were due to the strong affinity of mercapto group on the mercapto-functionalized hybrid sorbent with $\mathrm{Sb}$ (III) species and the weak affinity with $\mathrm{Sb}$ (v) species. ${ }^{23}$ The mercapto groups as "soft acid" owns a high affinity for "soft" $\mathrm{Sb}$ (III) species and a low affinity for "hard" $\mathrm{Sb}(\mathrm{v})$ species according to the hard-soft acid-bases theory. ${ }^{24}$ The relatively high 


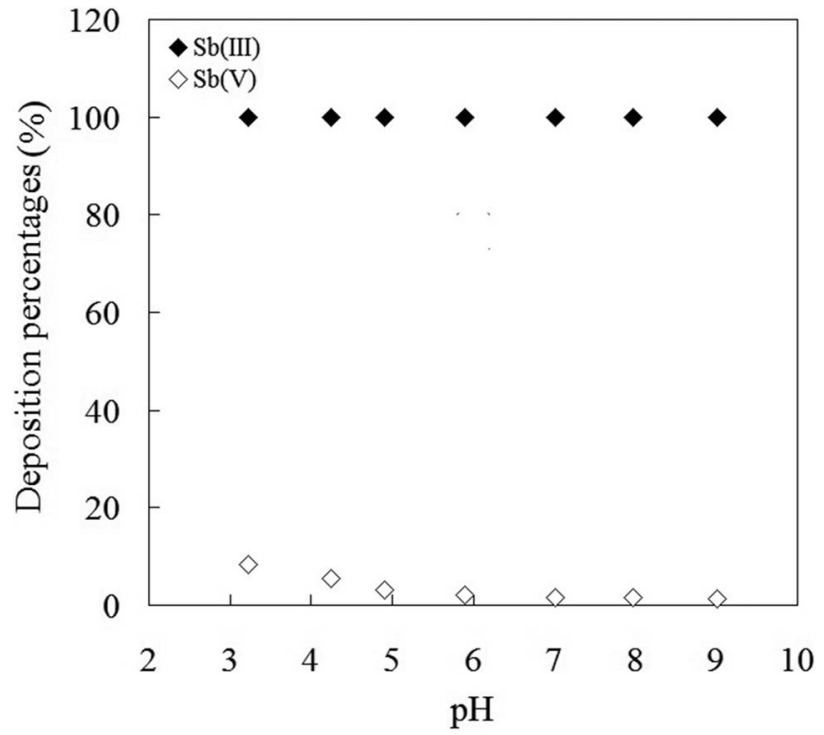

Fig. 2 Effect of $\mathrm{pH}$ of the sample solution on the deposition percentage of $\mathrm{Sb}(\mathrm{III})$ ions onto mercapto-functionalized hybrid sorbent.

enrichment efficiencies of $\mathrm{Sb}(\mathrm{v})$ species at strongly acidic conditions were observed for a comparison with the weak acidic and alkaline conditions. To achieve high efficiency and good selectivity, a $\mathrm{pH}$ of 5.0 was selected for the subsequent work.

\subsection{Effect of the amount of sorbent}

The amount of the sorbent is another important factor on the column studies for the quantitative recovery of $\mathrm{Sb}$ (III) species. Effect of the different amounts of mercapto-functionalized hybrid sorbent as SPE extractant on the deposition percentage of $\mathrm{Sb}$ (III) species was investigated in the range of $25-200 \mathrm{mg}$. Aliquots of $5.0 \mathrm{~mL}$ of $10 \mu \mathrm{g} \mathrm{L} \mathrm{L}^{-1} \mathrm{Sb}$ (III) species solutions were separately introduced into a series of packed columns containing different amounts of mercapto-functionalized hybrid sorbent. After passing solutions through the column, the deposition percentages of $\mathrm{Sb}(\mathrm{III})$ species on the mercaptofunctionalized hybrid sorbent were calculated. The results are depicted in Fig. 3. The high deposition percentages of $\mathrm{Sb}$ (III) species (>99\%) were achieved in the range of $100-200 \mathrm{mg}$ of the mercapto-functionalized hybrid sorbent. After that, deposition percentage of $\mathrm{Sb}(\mathrm{III})$ species onto mercapto-functionalized hybrid sorbent was found to be constant. Therefore, $100 \mathrm{mg}$ of mercapto-functionalized hybrid sorbent as SPE extractant was used in all the subsequent experiments.

\subsection{Effect of sample flow rate}

One of the parameters affecting the recovery and preconcentration is the sample flow rate, which is a decisive factor of the contact time between the sample solution and the sorbent. The influences of the flow rate of the sample solution for the deposition percentages of analytes were investigated by pumping aliquots of $20.0 \mathrm{~mL}$ of $10.0 \mu \mathrm{g} \mathrm{L}^{-1} \mathrm{Sb}$ (III) species solutions at $\mathrm{pH}$ of 5.0 into a packed column containing $100 \mathrm{mg}$ of mercapto-

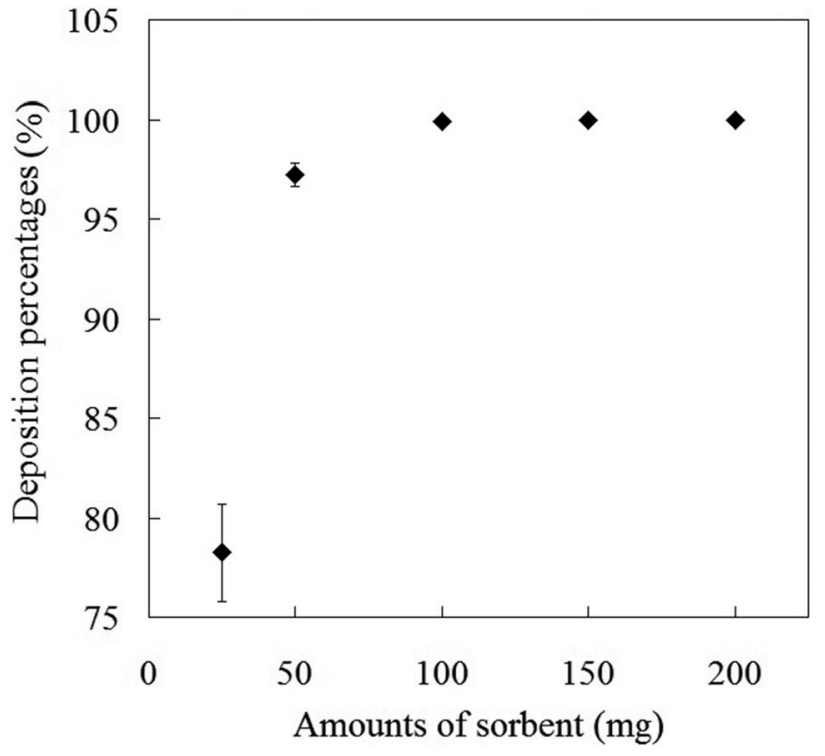

Fig. 3 Effect of the amount of extractant on the deposition percentage of $\mathrm{Sb}$ (III) ions onto mercapto-functionalized hybrid sorbent.

functionalized hybrid sorbent at different flow rates ranges of 1-20 $\mathrm{mL} \mathrm{min}^{-1}$. The flow rate was adjusted simply by connecting the adsorbing column to a flask, which was under controllable vacuum. The results indicated that the sample flow rate variations in the range of $2-10 \mathrm{~mL} \mathrm{~min}^{-1}$ had no significant effect on the deposition percentages of $\mathrm{Sb}$ (III) species onto mercapto-functionalized hybrid sorbent (as shown in Fig. 4). It can be seen from Fig. 4 that the adsorption of the $\mathrm{Sb}$ (III) species onto mercapto-functionalized hybrid sorbent is a relatively rapid kinetic process. In order to decrease in analysis time and

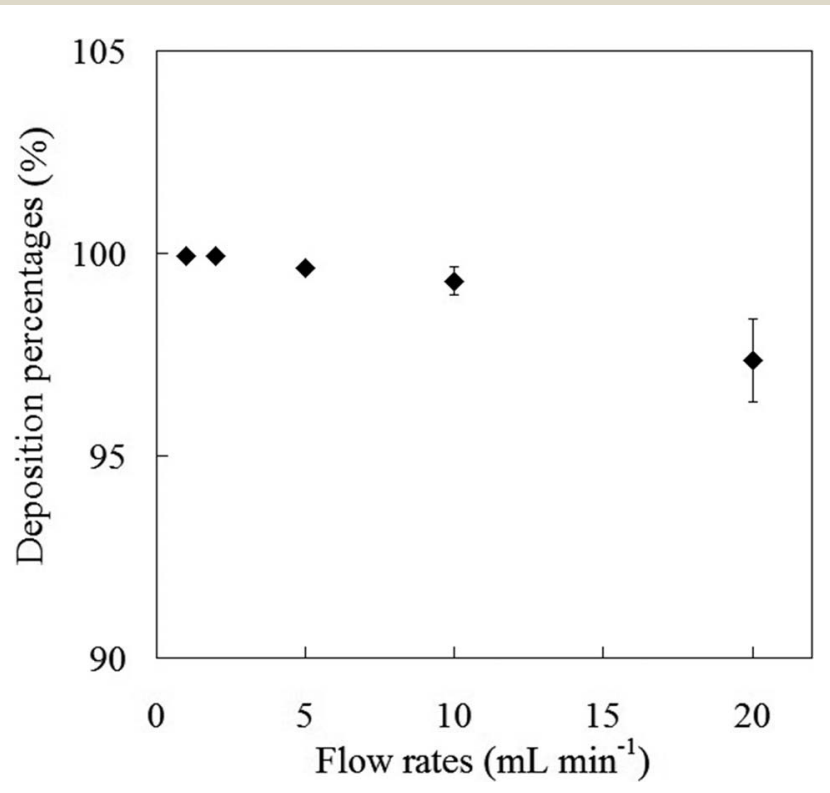

Fig. 4 Effect of sample flow rate on the deposition percentage of $\mathrm{Sb}(\mathrm{III})$ ions onto mercapto-functionalized hybrid sorbent. 
achieve a good precision, all the further studies were performed at the sample flow rate of $5.0 \mathrm{~mL} \mathrm{~min}^{-1}$.

\subsection{Optimization of elution conditions}

3.5.1 Type and concentration of eluent. Hydrochloric and nitric acid were used as the eluents for the desorption of $\mathrm{Sb}$ (III) species from mercapto-functionalized hybrid sorbent in SPE column. In the wide $\mathrm{pH}$ range of $2-11$, the $\mathrm{Sb}(\mathrm{OH})_{3}$ is the principal species. $\mathrm{Sb}(\mathrm{OH})_{4}{ }^{-}$dominates only above $\mathrm{pH} 11.8$, whereas the cationic form $\mathrm{Sb}(\mathrm{OH})_{2}{ }^{+}$is predominant at $\mathrm{pH}<1.4 .^{25}$ The desorption percentage of the eluent with different concentration was investigated by taking volumes of $5.0 \mathrm{~mL}$ at $5 \mathrm{~mL} \mathrm{~min}^{-1}$ flow rate of the each eluent. The results for this experiment are summarized in Table 1 . The results showed that the desorption percentages for $\mathrm{Sb}$ (III) species using $5 \%$ and $10 \%$ of acids as eluent were higher than with $1 \%$ of acids. The desorption percentages of $\mathrm{Sb}$ (III) species were more than $95 \%$ with $5 \%$ and $10 \% \mathrm{HCl}$ solution or $\mathrm{HNO}_{3}$ solution. There were no notable difference of desorption percentages between $5 \%$ and $10 \%$ of acids. The desorption of $\mathrm{Sb}$ (III) species from mercapto-functionalized hybrid sorbent was due to the protonation of mercapto groups and the competition between $\mathrm{H}^{+}$and $\mathrm{Sb}(\mathrm{OH})_{2}{ }^{+}$ions. ${ }^{18}$ Compared with $\mathrm{HNO}_{3}, \mathrm{HCl}$ is cheaper. Therefore, $5 \% \mathrm{HCl}$ solution was used as the effective eluent for the quantitative recovery of $\mathrm{Sb}(\mathrm{III})$ species.

3.5.2 Volume of eluent. To investigate the effect of the volume of eluent, various volumes (1-20 mL) of $5 \% \mathrm{HCl}$ solution were studied for desorption of the retained analytes from extractant. Effect of eluent volume on desorption percentages is shown in Fig. 5. It was found that $\mathrm{Sb}$ (III) species could be quantitatively recovered from extractant with the high desorption percentages $(>95 \%)$ when the volume range of eluent was more than $5.0 \mathrm{~mL}$. In the eluent volume lower than $5.0 \mathrm{~mL}$, the desorption percentages of the $\mathrm{Sb}$ (III) species were poor because of insufficient eluent volume. For achieving the higher enrichment factor, $5.0 \mathrm{~mL}$ of eluent was used in the following experiments.

3.5.3 Flow rate of eluent. Flow rate of eluent solution is one of important factors for the quantitative recoveries and desorption of $\mathrm{Sb}$ (III) species from mercapto-functionalized hybrid sorbent. The influence of the flow rate of eluent solution for the recoveries of $\mathrm{Sb}$ (III) species was investigated in the flow rate ranges of $1.0-20.0 \mathrm{~mL} \mathrm{~min}^{-1}$ (as presented in Fig. 6). The desorption percentages for $\mathrm{Sb}$ (III) species were more than $95 \%$ high in the flow rates range from $1.0 \mathrm{~mL} \mathrm{~min}^{-1}$ to 5.0

Table 1 Effect of eluents on the desorption of Sb(III) ions

\begin{tabular}{ll}
\hline Eluents & $\begin{array}{l}\text { Desorption } \\
\text { percentages (\%) }\end{array}$ \\
\hline $1 \%$ of $\mathrm{HNO}_{3}$ solution & $85.8 \pm 3.3$ \\
$5 \%$ of $\mathrm{HNO}_{3}$ solution & $96.2 \pm 2.2$ \\
$10 \%$ of $\mathrm{HNO}_{3}$ solution & $97.4 \pm 2.0$ \\
$1 \%$ of $\mathrm{HCl}$ solution & $84.9 \pm 2.9$ \\
$5 \%$ of $\mathrm{HCl}$ solution & $96.4 \pm 2.1$ \\
$10 \%$ of $\mathrm{HCl}$ solution & $97.1 \pm 1.9$
\end{tabular}

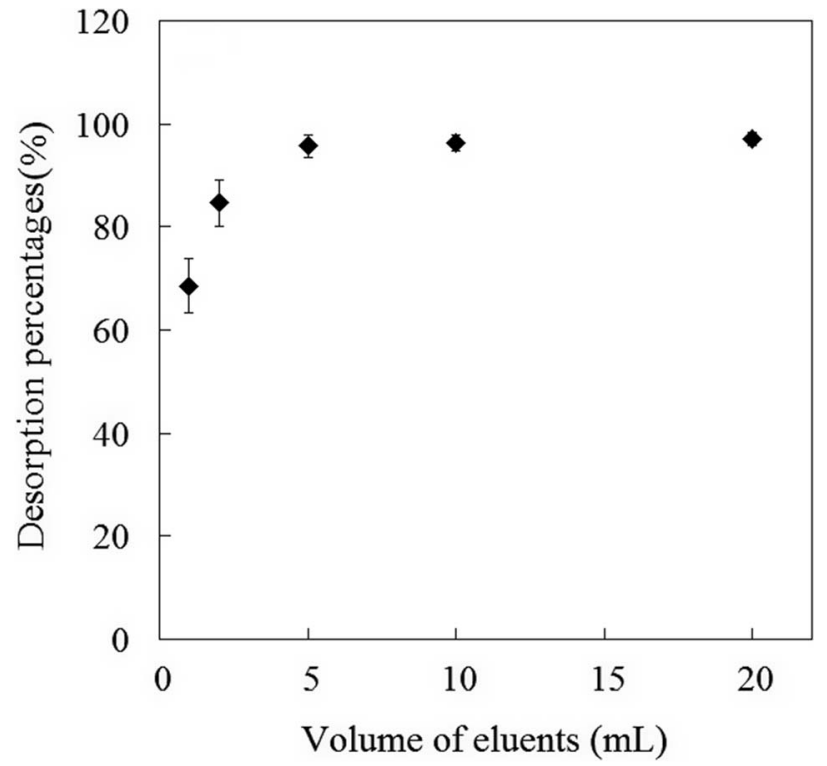

Fig. 5 Effect of eluent volume on the desorption percentage of Sb(III) ions from mercapto-functionalized hybrid sorbent.

$\mathrm{mL} \min ^{-1}$. In posterior experiments, the flow rate of eluent solution was kept constant at $5.0 \mathrm{~mL} \mathrm{~min}^{-1}$.

\subsection{Breakthrough volume}

$\mathrm{Sb}$ (III) species were quantitatively retained from the different sample volumes of 50-1000 $\mathrm{mL}$ containing the same amounts of metal ions $(2.5 \mathrm{mg})$. The deposition percentage for $\mathrm{Sb}$ (III) species was very efficient ( $>95 \%$ ) for the sample volume up to $1000 \mathrm{~mL}$. Consequently, by considering the final elution volume of $5.0 \mathrm{~mL}$ of $5 \% \mathrm{HCl}$ solution and the break through volume of

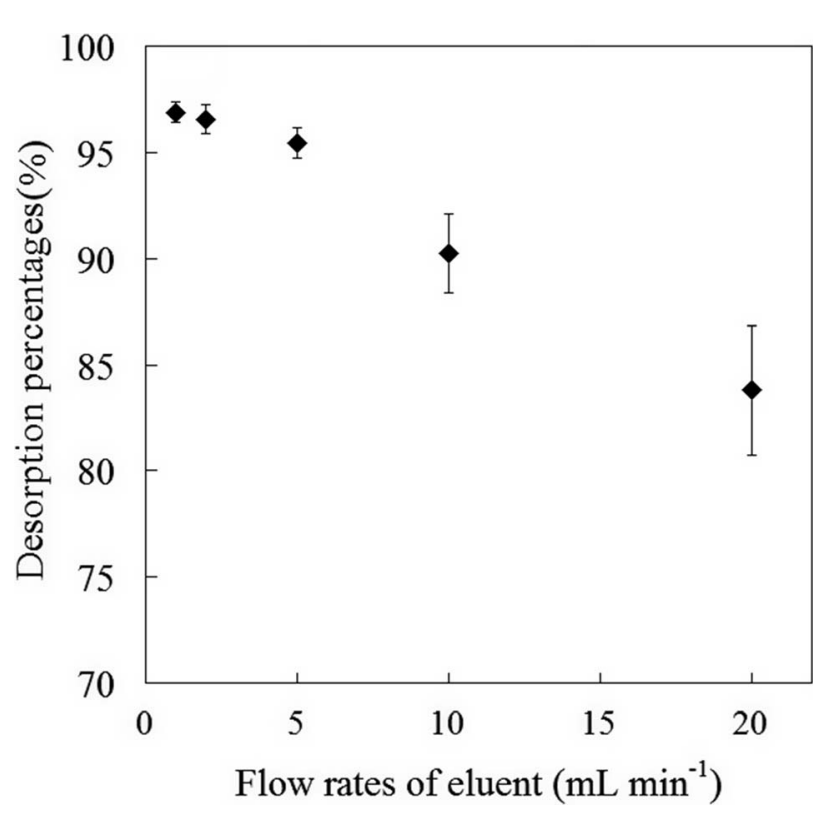

Fig. 6 Effect of eluent flow rate on the desorption percentage of $\mathrm{Sb}$ (III) ions from mercapto-functionalized hybrid sorbent. 
$1000 \mathrm{~mL}$, a preconcentration factor of 200 could be obtained easily. However, in order to decrease the analysis time, sample volumes of $250 \mathrm{~mL}$ was used for the preparation of calibration curves with a preconcentration factor of 50 .

\subsection{Interference studies}

In order to examine the effect of coexisting ions on the determination of $\mathrm{Sb}(\mathrm{III})$ species in the optimum conditions, the interferences of coexisting ions in binary mixtures containing $\mathrm{Sb}$ (III) species and one of the foreign ions were investigated on percent recovery of $\mathrm{Sb}(\mathrm{III})$ species. After introducing the binary solution into the column, the adsorbed $\mathrm{Sb}$ (III) species were eluted by $5.0 \mathrm{~mL}$ of $5 \% \mathrm{HCl}$ solution at the flow rate of 5.0 $\mathrm{mL} \min ^{-1}$. Then the content of $\mathrm{Sb}$ (III) species in the effluents was determined using HG-AFS and the recoveries were calculated. Any deviation of $\pm 5 \%$ or more from the absorbance value of the standard solution was considered as interference. The results are presented in Table 2 . The results indicated that most of the tested ions except $\mathrm{Fe}(\mathrm{III})$ ion had no notable influence on the determination of $\mathrm{Sb}$ (III) species. The following tolerance amount ratios were obtained: 5000 for $\mathrm{Mg}$ (II) and $\mathrm{Ca}(\mathrm{II}), 1000$ for $\mathrm{Zn}$ (II), $\mathrm{Cu}(\mathrm{II}), \mathrm{Co}(\mathrm{II}), \mathrm{Ni}(\mathrm{II}), \mathrm{Pb}(\mathrm{II})$, and $\mathrm{Cd}(\mathrm{II})$, and 500 for $\mathrm{Cr}(\mathrm{III})$ and As(III). The interfering effect of Fe(III) ions can be improved by the addition of excess amounts of $\mathrm{F}(\mathrm{I}-)$ ions $\left(1 \times 10^{-2} \mathrm{~mol} \mathrm{~L}^{-1}\right)$ to the sample solution prior to its introduction into the column. The tolerance ratio of Fe(III) ions can be improved to 500 . The results showed that the interferences of most foreign ions for the preconcentration of $\mathrm{Sb}$ (III) species in real samples were negligible.

\subsection{Analytical performance}

The calibration curve was obtained by using $250 \mathrm{~mL}$ of $0.010-$ $10.0 \mu \mathrm{g} \mathrm{L}^{-1} \mathrm{Sb}$ (III) species solutions at the optimum condition. The contents of $\mathrm{Sb}$ (III) species in eluting solutions were determined by HG-AFS. The linear calibration curve was observed in the concentration range of $1.0-200.0 \mu \mathrm{g} \mathrm{L}^{-1}$ for $\mathrm{Sb}(\mathrm{III})$ species. The regression coefficient of calibration curve was 0.9905 . The

Table 2 Effects of the foreign ions on the recovery of $10.0 \mu \mathrm{g} \mathrm{L}^{-1}$ of $\mathrm{Sb}(I I I)$ ions

\begin{tabular}{lll}
\hline & $\begin{array}{l}\text { Tolerance ratios } \\
\left(C_{\text {foreign ions }} / C_{\text {SbIII }}\right)\end{array}$ & Recovery (\%) \\
\hline Foreign ions & 5000 & $97.1 \pm 0.8$ \\
$\mathrm{Ca}(\mathrm{II})$ & 5000 & $97.9 \pm 0.4$ \\
$\mathrm{Cd}(\mathrm{II})$ & 1000 & $98.1 \pm 0.4$ \\
$\mathrm{Zn}(\mathrm{II})$ & 1000 & $98.6 \pm 1.6$ \\
$\mathrm{Cu}(\mathrm{II})$ & 1000 & $98.6 \pm 0.7$ \\
$\mathrm{~Pb}(\mathrm{II})$ & 1000 & $99.1 \pm 0.4$ \\
$\mathrm{Co}(\mathrm{II})$ & 1000 & $98.4 \pm 0.6$ \\
$\mathrm{Ni}(\mathrm{II})$ & 1000 & $97.8 \pm 0.6$ \\
$\mathrm{As}(\mathrm{III})$ & 500 & $95.7 \pm 1.7$ \\
$\mathrm{Cr}(\mathrm{III})$ & 500 & $97.8 \pm 1.6$ \\
$\mathrm{Fe}(\mathrm{III})^{a}$ & 500 & $95.8 \pm 2.6$
\end{tabular}

${ }^{a}$ The concentration of $\mathrm{F}(\mathrm{I}-)$ ion is $0.01 \mathrm{~mol} \mathrm{~L}^{-1}$ and $\mathrm{F}(\mathrm{I}-)$ ion in solution is excess.
Table 3 The results for the determination of $\mathrm{Sb}$ in the certified reference materials

\begin{tabular}{llc}
\hline CRMs & Certified value & Found value \\
\hline SLRS-5 & $0.23 \mathrm{mg} \mathrm{L}^{-1 a}$ & $0.21 \pm 0.03 \mathrm{mg} \mathrm{L}^{-1}$ \\
GBW(E) 080696 & $9.87 \mathrm{mg} \mathrm{L}^{-1 a}$ & $9.9 \pm 0.1 \mathrm{mg} \mathrm{L}^{-1}$ \\
GBW07309 & $0.81 \pm 0.23 \mathrm{mg} \mathrm{kg}^{-1}$ & $0.90 \pm 0.2 \mathrm{mg} \mathrm{kg}^{-1}$
\end{tabular}

${ }^{a}$ Indicative value.

relative standard deviations (RSD) for eleven replicate measurements at a concentration level of $10 \mu \mathrm{g} \mathrm{L^{-1 }}$ of $\mathrm{Sb}(\mathrm{III})$ species was $1.6 \%$. The values of the detection limits (LOD), defined as the concentration of analyte giving signals equivalent to three times, the standard deviation of the blank signal plus the net blank intensity were found to be $2 \mathrm{ng} \mathrm{\textrm {L } ^ { - 1 }}$ when $250 \mathrm{~mL}$ of solution was preconcentrated to a final volume of $5.0 \mathrm{~mL}$. The instrumental LOD for $\mathrm{Sb}$ (III) species was also determined by using blank solutions without preconcentration and found to be $0.1 \mu \mathrm{g} \mathrm{L}^{-1}$ for comparison.

\subsection{Analysis of standard reference materials}

The accuracy of the proposed method was investigated by examining the standard reference materials (SLRS-5 trace elements in river water, GBW(E) 080696 antimony component analysis solution and GBW07309 stream sediment) following the experimental procedure. The total concentrations of Sb in standard reference materials are known, whereas the speciation of $\mathrm{Sb}$ in the standard reference materials is unknown. In order to test the accuracy of the proposed method, the standard reference materials were diluted appropriately with $5 \% \mathrm{HCl}$ solution and $5 \mathrm{~mL}$ of $10 \%$ vitamin $\mathrm{C}$ solution. The vitamin $\mathrm{C}$ was excess by calculation. The excess vitamin $\mathrm{C}$ can reduce $\mathrm{Sb}(\mathrm{v})$ to $\mathrm{Sb}$ (III) and can ensure the existence of antimony as $\mathrm{Sb}$ (III)

Table 4 Analytical application

\begin{tabular}{|c|c|c|c|}
\hline Samples & $\begin{array}{l}\mathrm{Sb}(\mathrm{III}) \\
\text { added }\left(\mu \mathrm{g} \mathrm{L}^{-1}\right)\end{array}$ & $\begin{array}{l}\mathrm{Sb}(\mathrm{III}) \text { found }^{a} \\
\left(\mu \mathrm{g} \mathrm{L}^{-1}\right)\end{array}$ & $\begin{array}{l}\text { Recovery } \\
(\%)\end{array}$ \\
\hline \multirow[t]{3}{*}{ Pure water } & 0.00 & $\mathrm{LOD}^{b}$ & - \\
\hline & 5.0 & $4.9 \pm 0.2$ & $98 \pm 3$ \\
\hline & 10.0 & $10.2 \pm 0.3$ & $102 \pm 3$ \\
\hline \multirow{3}{*}{ Tap water } & 0.00 & LOD & - \\
\hline & 5.0 & $5.1 \pm 0.2$ & $102 \pm 4$ \\
\hline & 10.0 & $9.9 \pm 0.3$ & $99 \pm 3$ \\
\hline \multirow[t]{3}{*}{ Hun River } & 0.00 & LOD & - \\
\hline & 5.0 & $4.9 \pm 0.2$ & $98 \pm 3$ \\
\hline & 10.0 & $9.8 \pm 0.3$ & $98 \pm 3$ \\
\hline \multirow{3}{*}{$\begin{array}{l}\text { Mineral } \\
\text { wastewater }\end{array}$} & 0.00 & $33.5 \pm 1.3$ & - \\
\hline & 5.0 & $38.3 \pm 0.9$ & $96 \pm 3$ \\
\hline & 10.0 & $43.7 \pm 1.5$ & $102 \pm 4$ \\
\hline \multirow[t]{3}{*}{ Sea water } & 0.00 & LOD & - \\
\hline & 5.0 & $4.8 \pm 0.3$ & $96 \pm 6$ \\
\hline & 10.0 & $9.5 \pm 0.5$ & $95 \pm 5$ \\
\hline
\end{tabular}

${ }^{a}$ Mean $\pm \mathrm{SD}$ for three replicate measurements of three individual preparations. ${ }^{b}$ Below detection limit. 
Table 5 Comparison of analytical performance with other SPE extractants reported in the literature for Sb(III) species

\begin{tabular}{lllc}
\hline SPE extractants & LOD $\left(\mathrm{ng} \mathrm{L}^{-1}\right)$ & Precision (\%) & Recovery (\%) \\
\hline Silica-based octyl sorbent & 1 & - & $90.2-114$ \\
Multi-walled carbon nanotubes & 3.5 & 4.8 & $96-104.1$ \\
$\mathrm{C}_{8}-\mathrm{Fe}_{3} \mathrm{O}_{4} @ \mathrm{SiO}_{2}$ nanoparticles & 1 & 3.4 & $91-105$ \\
$\mathrm{Nano} \gamma$-alumina & 6 & 2.8 & $93-107$ \\
Single-walled carbon & 2.1 & 4.8 & $92-106.5$ \\
Functionalized mesoporous silica & 1 & 0.9 & $91.3-109.9$ \\
$\mathrm{TiO}_{2}$ & 140 & 6.8 & $103-120$ \\
$\mathrm{C}_{16}$-bonded silica gel & 7 & 3.8 & -10 \\
Dowex $1 \times 8-200$ & 2000 & 3.1 & $92.8-102.5$ \\
Yeast immobilized polyurethane foam & 150 & - & $81-113$ \\
Mercapto-functionalized hybrid & 2.5 & 1.6 & $95-102$
\end{tabular}

species in the standard reference materials aqueous solution. The results were found to be in good agreement with the certified values (as seen in Table 3). These values revealed that there was no significant difference between the certified values and the measured values by performing $t$-test at $95 \%$ confidence limit, thus confirming the accuracy of the proposed procedure.

\subsection{Applications}

In order to assess the applicability of the proposed procedure to the analysis of real samples including pure water, tap water, river water (from the Hun River, Shenyang, China), mineral wastewater and sea water, were analyzed according to the general procedure. The correctness of results was verified by analyzing the concentration after the addition of known amounts of $\mathrm{Sb}(\mathrm{III})$ species into water samples. Different amounts of the investigated $\mathrm{Sb}$ (III) species were spiked by adding 1.250 and $2.50 \mu \mathrm{g}$ of $\mathrm{Sb}$ (III) species in a water sample and diluting to $250 \mathrm{~mL}$ and the resulting solutions were submitted to the preconcentration procedure. The results (deducted the reagents blank) are shown in Table 4 . The recovery values for $\mathrm{Sb}$ (III) species were found to be in the range of $95-102 \%$ for spiked $\mathrm{Sb}$ (III) species. Good agreement was achieved between the added and found concentrations of analytes using the proposed procedure. A comparison of the analytical performance obtained by the proposed method with other extractants reported in the literature for $\mathrm{Sb}$ (III) species is shown in Table $5 .^{7-12,26}$ As can be seen, the relative low LOD of the proposed method were obtained with other SPE extractants reported in the literature for $\mathrm{Sb}$ (III) species for comparison. The proposed method had the lowest precision except the results reported in the ref. 12, and had also the narrowest range of recovery. The results indicated that mercapto-functionalized hybrid sorbent was suitable for the selective separation and preconcentration of $\mathrm{Sb}$ (III) species at the $\mu \mathrm{g} \mathrm{\textrm {L } ^ { - 1 }}$ levels in real water samples.

\section{Conclusion}

By using mercapto-functionalized hybrid sorbents as SPE extractant, a simple, rapid, powerful, advanced, precise, accurate and reliable method was developed for the separation and preconcentration of $\mathrm{Sb}$ (III) species prior to the determination by HG-AFS analysis in real samples. The value of LOD was found to be $2 \mathrm{ng} \mathrm{\textrm {L } ^ { - 1 }}$ when a sample volume of $1000 \mathrm{~mL}$ was preconcentrated to a final volume of $5.0 \mathrm{~mL}$. The obtained optimum pH range was found to be at a range of 3-9. Most of the cations were free of interference for the preconcentration of $\mathrm{Sb}$ (III) species within a wide range of concentration. The results obtained by analyzing standard reference materials proved that the accuracy and precision of the proposed procedure were very good. The proposed procedure showed very good recoveries (95$102 \%$ ) of several water samples. Thus, mercapto-functionalized hybrid sorbent as the SPE extractant had been demonstrated to be promising for the routine laboratories in the determination of $\mathrm{Sb}(\mathrm{III})$ species even at very low concentration.

\section{Conflicts of interest}

There are no conflicts to declare.

\section{Acknowledgements}

Sponsored by the National Natural Science Foundation of China (grant no. 21477082 and 21107076) and by Liaoning Natural Science Foundation (grant no. 201602402).

\section{References}

1 (a) USEPA, Antimony: An Environmental and Health Effects Assessment, US Environmental Protection Agency, Office of Drinking Water, Washington, DC, 1984; (b) M. M. López Guerrero, E. Vereda Alonso, J. M. Cano Pavón, M. T. Siles Cordero and A. J. García de Torres, J. Anal. At. Spectrom., 2016, 31, 975-984.

2 M. Filella, N. Belzile and Y.-W. Chen, Earth-Sci. Rev., 2002, 59, 265-285.

3 M. Filella, N. Belzile and Y.-W. Chen, Earth-Sci. Rev., 2002, 57, 125-176.

4 N. Gurnani, A. Sharma and G. Tulukder, Nucleus, 1994, 37, 71-96.

5 (a) S. C. Apte, J. Anal. At. Spectrom., 1986, 1, 38-47; (b) Z. Li and Y. Guo, Talanta, 2005, 65, 1318-1325; (c) R. Wietecha, 
P. Kościelniak, T. Lech and T. Kielar, Microchim. Acta, 2005, 149, 137-144.

6 (a) V. Camel, Spectrochim. Acta, Part B, 2003, 58, 1177-1233; (b) Y. Zhai, Y. Liu, X. Chang, S. Chen and X. Huang, Anal. Chim. Acta, 2007, 593, 123-128; (c) E. M. Thurman and M. S. Mills, Solid-Phase Extraction, Principles and Practice, Wiley, New York, 1998; (d) M. M. López Guerrero, M. T. Siles Cordero, E. Vereda Alonso, J. M. Cano Pavón and A. García de Torres, J. Anal. At. Spectrom., 2015, 30, 1169-1178.

7 C. Yu, Q. Cai, Z. X. Guo, Z. Yang and S. B. Khoo, Analyst, 2002, 127, 1380-1385.

8 H. Fazelirad and M. A. Taher, Microchim. Acta, 2014, 181, 655-662.

9 P. Li, Y. Chen, X. Hu and H. Lian, Talanta, 2015, 134, 292297.

10 J. Tian, T. Huang and J. Lu, Food Anal. Methods, 2013, 6, 1080-1089.

11 H. Wu, X. Wang, B. Liu, Y. Liu, S. Li, J. Lu, J. Tian, W. Zhao and Z. Yang, Spectrochim. Acta, Part B, 2011, 66, 74-80.

12 M. M. López Guerrero, M. T. Siles Cordero, E. Vereda Alonso, A. J. García de Torres and J. M. Cano Pavón, Talanta, 2014, 129, 1-8.

13 K. Zih-Perényi, P. Jankovics, E. Sugár and A. Lásztity, Spectrochim. Acta, Part B, 2008, 63, 445-449.

14 A. Kaur and U. Gupta, J. AOAC Int., 2010, 93, 1302-1307.

15 A. Calvo Fornieles, A. García de Torres, E. Vereda Alonso and J. M. Cano Pavón, J. Anal. At. Spectrom., 2013, 28, 364-372.

16 G.-Z. Fang, J. Tan and X.-P. Yan, Anal. Chem., 2005, 77, 17341739.
17 (a) J. B. Wu, S. Y. Zang and Y. L. Yi, J. Sol-Gel Sci. Technol., 2013, 66, 434-442; (b) L. He, B. B. Wang, D. D. Liu, K. S. Qian and H. B. Xu, Korean J. Chem. Eng., 2014, 31, 343-349; (c) D. P. Sui, H. X. Chen and D. W. Li, J. Sol-Gel Sci. Technol., 2016, 80, 504-513.

18 D. Zhang, Y. Zhao and H.-B. Xu, Sep. Sci. Technol., 2017, 52, 1938-1945.

19 T.-L. Deng, Y.-W. Chen and N. Belzile, Anal. Chim. Acta, 2001, 432, 293-302.

20 (a) Buhani, Narsito, Nuryono and E. S. Kunarti, Desalination, 2010, 251, 83-89; (b) C. A. Quirarte-Escalante, V. Soto, W. Cruz, G. R. Porras, R. Manríquez and S. Gomez-Salazar, Chem. Mater., 2009, 21, 1439-1450.

21 (a) B. Viltužnik, A. Košak, Y. L. Zub and A. Lobnik, J. Sol-Gel Sci. Technol., 2013, 68, 365-373; (b) J. Wu, J. Xie, L. Ling, G. Ma and B. Wang, J. Coat. Technol. Res., 2013, 10, 849-857.

22 L. He, B.-B. Wang, D.-D. Liu, K.-S. Qian and H.-B. Xu, Korean J. Chem. Eng., 2014, 31, 343-349.

23 M. Matsui, K. Matsumoto and K. Terada, Anal. Chim. Acta, 1987, 193, 381-385.

24 H. Sun, S. C. Yan and W. S. Cheng, Eur. J. Biochem., 2000, 267, 5450-5457.

25 F. Wu, F. Sun, S. Wu, Y. Yan and B. Xing, Chem. Eng. J., 2012, 183, 172-179.

26 (a) L. Zhang, Y. Morita, A. Sakuragawa and A. Isozaki, Talanta, 2007, 72, 723-729; (b) S. Garbos, M. Rzepecka, E. Bulska and A. Hulanicki, Spectrochim. Acta, Part B, 1999, 54, 873-881; (c) F. S. Rojas, C. B. Ojeda and J. M. C. Pavón, Talanta, 2007, 72, 951-956; (d) A. A. Menegário, A. J. Silva, E. Pozzi, S. F. Durrant and C. H. Abreu, Spectrochim. Acta, Part B, 2006, 61, 1074-1079. 